\title{
REPENSANDO A DEGRADAÇÃO DO REGIME HÍBRIDO NA VENEZUELA DE UMA PERSPECTIVA MINIMALISTA DE DEMOCRACIA
}

\author{
André Silva de Oliveira \\ Universidade Federal de Pernambuco (UFPE). Recife/PE, Brasil. \\ Rodolfo Silva Marques \\ Autor correspondente. Faculdade de Estudos Avançados do Pará. Rodovia Augusto Montenegro, km 4 - Parque Verde. Belém/PA, \\ Brasil. CEP 66000-000. http://lattes.cnpq.br/7865990074375419. https://orcid.org/0000-0002-5855-0393. \\ rodolfo.smarques@gmail.com
}

Após a redemocratização que varreu a América Latina nos anos 80 do século 20, a literatura em Ciência Política assinalou o surpreendente advento das democracias iliberais - tão bem descritas por Fareed Zakaria em icônico artigo de 1997 - e/ou regimes híbridos, conforme produção científica recente. Tais arranjos políticos pretendem modificar substancialmente as instituições da democracia representativa do tipo liberal, substituindo-as por desenhos consonantes com as concepções de democracia participativa ou radical. A discussão ganhou notável contribuição com a recente publicação do livro "Como as democracias morrem" (2018), de Steven Levitsky e Daniel Ziblatt, que apresentam seu diagnóstico para a erosão gradual das instituições da democracia representativa do tipo liberal ao redor do planeta. O caso mais emblemático de regime híbrido na América Latina, segundo a literatura dominante, é o da Venezuela bolivariana, que exibe hoje profunda divisão política e está à beira do colapso econômico. Por meio da revisão da literatura e a partir de uma perspectiva minimalista de democracia, o presente artigo busca repensar as causas que levaram à ascensão e, agora, ao iminente colapso do regime bolivariano que substituiu a oligarquia competitiva representada pelo Pacto de Punto Fijo (1958-1998). As conclusões principais são, entre outras, a de que a robusta degradação do ambiente político-institucional venezuelano decorreu, no campo político, da miragem do outsider redentor e, na esfera econômica, do cálculo mágico de custo zero.

Palavras-chave: Regime híbrido; Venezuela; democracia; instituições.

\section{RETHINKING THE DEGRADATION OF THE HYBRID REGIME IN VENEZUELA} FROM A MINIMALIST PERSPECTIV OF DEMOCRACY

\section{ABSTRACT}

After the redemocratization that swept Latin America in the 1980s, literature on Political Science marked the starting advent of the illiberal democracies - as well described by Fareed Zakaria in the iconic 1997 article - and/or hybrid regimes, according to recent scientific production. Such political arrangements are intended to substantially modify the institutions of representative democracy of the liberal type, replacing them with designs consonant with conceptions of participatory or radical democracy. The discussion gained notable insight with the recent publication of Steven Levitsky and Daniel Ziblatt's book "How Democracies Die," which present their diagnosis for the gradual erosion of the institutions of representative democracy of the liberal type around the planet. The most emblematic case of a hybrid regime in Latin America, according to the dominant literature, is that of Bolivarian Venezuela, which today has a profound political divide and is on the verge of economic collapse. Through the literature review and from a minimalist perspective of democracy, this article seeks to rethink the causes that led to the rise and now to the imminent collapse of the Bolivarian regime that replaced the competitive oligarchy represented by the Punto Fijo Pact (1958 -1998). The main conclusions are, among others, that the robust degradation of the Venezuelan political-institutional environment was, in the political field, the mirage of the redemptive outsider and, in the economic sphere, the magical calculation of zero cost.

Keywords: Hybrid Regime; Venezuela; democracy; institutions.

Recebido em: $18 / 3 / 2021$

Aceito em: 18/10/2021 


\section{INTRODUÇÃO}

Considerando-se os anos 1970 e 1980, a terceira onda de redemocratização que varreu as ditaduras da Europa Ocidental - Portugal, Espanha e Grécia à frente - e, depois, América Latina, Ásia e África, foi surpreendentemente seguida não pela consolidação de democracias constitucionais, mas pelo advento de democracias iliberais como apontou, com evidente acerto, Zakaria Fareed em icônico artigo (1997). Esse fenômeno originou uma extensa literatura em Ciência Política e outras áreas do conhecimento que passaram a classificar as democracias iliberais de regimes híbridos, uma vez que reuniriam simultaneamente características democráticas e autoritárias, embora modifiquem as regras eleitorais em desfavor dos desafiantes, beneficiando, assim, os incumbentes (KORNBLITH, 2013, p. 49; CORRALES, 2015, p. 37).

É um fenômeno que contraria a ideia - equivocadamente difundida logo após o colapso do comunismo soviético e do bloco monolítico formado pelos países do Pacto de Varsóvia - de que a democracia liberal se constituiria no modelo global predominante, praticamente incontrastável, vale dizer, sem uma alternativa crível capaz de permitir a compatibilização entre democracia eleitoral e crescimento econômico por meio do livre mercado. $\mathrm{O}$ advento dos regimes híbridos soterrou qualquer pretensão à ideia de uma inevitabilidade histórica do liberalismo ou, para ser mais exato, do triunfo definitivo da democracia representativa do tipo liberal. Os experimentos realizados pelos regimes híbridos, no entanto, têm apresentado falhas que remetem à sua incapacidade de promover um novo desenho institucional credível sem sacrificar completamente a concepção minimalista de democracia, na esteira da herança schumpeteriana. Assim, as eleições promovidas pelos regimes híbridos, em lugar de sinalizarem sua legitimação pelo reconhecimento consensual dos seus resultados, são apontadas como simulacros de competições igualitárias em virtude dos constrangimentos formais e informais criados à atuação da oposição.

De fato, nos regimes híbridos, a concentração de poderes no Executivo tem sido extraordinária, a ponto de chegar a solapar completamente o sistema de freios e contrapesos (checks and balances) entre os ramos de poder. Em contraste com o passado, a erosão das instituições típicas da democracia do tipo liberal não se faz mais hoje pelo recurso traumático aos golpes militares de Estado - tal como sucedeu, por exemplo, no Chile em 1973 com a violenta derrubada do governo de Salvador Allende - mas ocorre de forma gradual e sequencial, por dentro, como sucedeu em diversos experimentos à direita (o fujimorismo no Peru) e à esquerda (o bolivarianismo na Venezuela) do espectro político-ideológico.

Como é amplamente reconhecida pela literatura, a Venezuela bolivariana se constitui em um caso emblemático de regime híbrido na América Latina (DIAMOND, 2002; LEVINE, 2002; LEVINE; MOLINA, 2012; KORNBLITH, 2013; CORRALES, 2015; URRIBARÍ, 2015; GAMBOA, 2016). Os crescentes constrangimentos criados pelo regime bolivariano à contestação pública - seja à atuação dos partidos de oposição, seja dos movimentos civis ou mesmo da imprensa independente - merecem especial atenção pela excepcionalidade do caso, mesmo tendo em conta a forte tradição iliberal do continente latino-americano.

O escopo do presente artigo não é, portanto, classificar a Venezuela bolivariana como regime híbrido, dado que este entendimento já é pacífico na literatura, mas apresentar pelo menos dois argumentos principais para a progressiva e robusta degradação do ambiente polí- 
tico-institucional e econômico: no campo político, a miragem do outsider redentor e, na esfera econômica, o cálculo mágico de custo zero. O leitmotiv para a referida degradação consiste na incapacidade de manter as características básicas da concepção minimalista de democracia. Assim, antes de ingressar na análise das causas apontadas para a degradação do ambiente político-institucional e econômico do regime chavista, cumpre definir sinteticamente o que pode ser classificado como democracia em sua concepção ou versão mínima e por que suas salvaguardas importam para a sua preservação.

\section{POR QUE IMPORTAM AS SALVAGUARDAS DA DEMOCRACIA MINIMALISTA}

Democracia é um conceito claramente polissêmico, entendimento que se estende, por óbvio, à sua concepção minimalista. A despeito disso, porém, alguns breves delineamentos são necessários para os objetivos aqui perseguidos. O primeiro ponto é que a concepção minimalista deve ser entendida como associada intrinsecamente ao funcionamento das instituições da democracia representativa do tipo liberal, condição necessária e antecedente às formas idealizadas e/ou efetivamente experimentadas de democracia máxima ou participativa. Nosso entendimento consiste no reconhecimento de que a concepção da democracia como fórum não pode prescindir da proteção dos mecanismos que objetivem salvaguardar os direitos civis e políticos dos indivíduos, participantes ou não da arena pública.

O segundo aspecto reside na indicação de quais mecanismos ou salvaguardas são indispensáveis, segundo a literatura clássica, para caracterizar uma democracia como mínima. As concepções teóricas de Joseph Schumpeter, Karl Popper e Robert Dahl fornecem roteiros adequados neste sentido. A miríade de regimes híbridos que surgiu após o fim da guerra fria justifica que se revisite tais teóricos.

A contribuição de Schumpeter (2013) é reputada como seminal na Ciência Política dado o seu caráter instrumental e não normativo. Ao descrever a democracia representativa do tipo liberal como a mera competição eleitoral entre grupos políticos distintos que almejam a conquista do poder, Schumpeter conferiu-lhe uma dimensão instrumental de natureza reducionista. Essa concepção minimalista, todavia, deixa de levar em conta outros componentes essenciais ao funcionamento da democracia representativa do tipo liberal, como o fato de que, no período entre eleições, as instituições seguem atuando no controle dos atos dos governantes. O cidadão mediano - convocado periodicamente para escolher qual grupo político governará - tem, assim, à sua disposição espaços institucionais assegurados nos quais pode reivindicar o aperfeiçoamento da democracia.

Obviamente, a competição entre elites políticas deve ocorrer por meio de eleições livres, justas e universais para que obtenha a necessária legitimidade. Dito de outro modo, eleições justas e limpas forjam o indispensável consenso acerca dos seus resultados, bem como acenam para os vencidos com a possibilidade de que, no futuro, também possam vir a ocupar o poder político. Tais aspectos do pensamento schumpeteriano são relevantes para a discussão porque as eleições, como procedimentos essenciais à legitimidade da democracia, são frequentemente pervertidas pelos regimes híbridos pela instituição de uma série de mecanismos que constrangem a atuação da oposição leal, impedindo-a de chegar a conquistar o governo. No caso venezuelano, por exemplo, a organização Human Rigths Watch (HRW) considera, desde o seu relatório de 2009, que o país deixou de ser uma democracia eleitoral 
(LEVINE; MOLINA, 2012, p. 161). Os constrangimentos criados pelo regime bolivariano à atuação dos grupos opositores são demasiado evidentes, indo da forte regulação de conteúdo da imprensa ou mídia independente à robusta modificação das regras eleitorais em desfavor dos desafiantes. O regime bolivariano segue, na verdade, um padrão de mudança institucional comum aos países latino-americanos. Steven Levitsky e María Murillo (2013, p. 94-95) afirmam que as mudanças institucionais na América Latina não obedecem a um modelo contínuo e gradualista, mas, ao reverso, têm sido frequentes e radicais, engendrando um padrão que classificaram de "substituição em série" (no original, serial replacement). Entre os exemplos abundantes de substituição em série produzidos pela América Latina, Levitsky e Murillo (2013, p. 95) citam o caso emblemático da Bolívia que, no século 19, editou dez constituições (1826, 1831, 1834, 1839, 1843, 1851, 1861, 1868, 1871 e 1878).

Por seu turno, Popper (1998, p. 140) caracterizou a democracia como a alternância de grupos políticos no poder sem derramamento de sangue. Esta seria a distinção crucial, na perspectiva popperiana, entre democracias e tiranias. Com evidente acerto, porém, Popper adverte que, em contextos específicos, a maioria pode preferir substituir uma democracia em dificuldades por uma ditadura benevolente. A teoria democrática em Popper (1998, p. 140141) traz uma série de prescrições sobre como proteger a democracia dos ataques dos que querem demolir suas instituições, mas reconhece que nunca foi possível criar salvaguardas capazes de evitar essa transição para o fim da liberdade política. Assim, o princípio democrático predominante não recairia - ao menos, não exclusivamente - na vontade da maioria, mas na instituição de controles que protegessem as instituições:

Encarada de tal ângulo, a teoria da democracia não se baseia no princípio de que a maioria deve governar, mas, antes, no de que diversos métodos igualitários para o controle democrático, tais como o sufrágio universal e o governo representativo, devem ser considerados como simplesmente salvaguardas institucionais, de eficácia comprovada pela experiência, contra a tirania, repudiada de modo geral como forma de governo. E estas instituições devem ser suscetíveis de aperfeiçoamento (POPPER,1998, p. 140-141).

De fato, nem então nem tampouco agora a democracia representativa do tipo liberal, que Popper defendia com vigor como modelo de sociedade aberta resultante de um longo processo histórico de lutas políticas, logrou criar salvaguardas que pudessem impedir a erosão de suas instituições por grupos radicais ou intransigentes. O ostracismo - pena de exílio temporário aplicada aos inimigos da democracia ateniense - pode ser interpretado como uma das mais antigas salvaguardas de que se tem notícia na história política do Ocidente. Modernamente, as eleições - realizadas de modo livre e periodicamente - podem ser reputadas como salvaguardas necessárias, mas não se constituem em procedimento suficiente para evitar a eventual substituição da democracia do tipo liberal por regimes híbridos.

Vinculado à tradição pluralista, Robert Dahl concebeu a democracia como uma poliarquia na qual a competição oligárquica e a participação política se constituem em variáveis que, uma vez expandidas, produzem melhor resultado para o aperfeiçoamento das instituições. Com grande acuidade e como que antevendo o surgimento dos regimes híbridos no período pós-guerra fria, Dahl ponderou sobre o dilema que consiste em realizar eleições reprimindo a atuação da oposição: 
É dispensável dizer que, na falta do direito de exercer oposição, o direito de "participar" é despido de boa parte do significado que tem num país onde existe a contestação pública. Um país com sufrágio universal e com um governo totalmente repressivo certamente proporcionaria menos oportunidades a oposições do que um país com um sufrágio limitado, mas com um governo fortemente tolerante (DAHL, 2005, p. 28-29).

Não se concebe mais que os regimes políticos deixem de realizar eleições universais e periódicas, pois, caso isto ocorresse, implicaria a admissão explícita do fim da democracia e certamente a condenação da comunidade internacional, advindo daí uma série de sanções políticas e, sobretudo, econômicas de graves consequências. Poucos países se aventuram, portanto, a suprimir os procedimentos eleitorais, considerando o consenso universal forjado a respeito de sua necessidade como condição essencial para a caracterização de cada sistema político como democrático.

Ocorre, porém, que, como Dahl bem ressaltou, a repressão - talvez o mais correto seja se falar hoje em robustos constrangimentos institucionais - à atuação da oposição frustra o direito à participação, esvaziando fortemente a esfera destinada à contestação pública. Sem amplos e igualitários espaços assegurados à atuação da oposição, imprensa ou mídia livre, movimentos civis independentes, etc., as instituições da democracia representativa fenecem e podem, no limite, chegar à sua completa erosão.

Isso posto, os autores da concepção de democracia minimalista enfatizam que, embora apresente uma natureza limitativa, a competição eleitoral universal, periódica, igualitária e, portanto, justa entre grupos e/ou partidos políticos, constitui-se em condição fundamental para a legitimidade das instituições democráticas.

Historicamente, a concepção minimalista de democracia assenta-se sobre a ideia de competição eleitoral entre grupos políticos compatibilizada com o funcionamento do livre mercado. Forjou-se, assim, o entendimento de que a democracia como mercado necessita desses dois pilares que se retroalimentam incessantemente para manter a vitalidade e o aperfeiçoamento contínuo das suas instituições. Regimes híbridos, todavia, modificam sistematicamente as regras eleitorais para frustrar competições oligárquicas minimamente equitativas, vulnerando, assim, uma condição básica para a caracterização de um sistema político como democrático, ainda que se tenha em mente sua concepção minimalista. No mesmo passo, o controle estatal robusto das atividades econômicas pelos regimes híbridos produz desenhos institucionais em que a liberdade política definha de modo gradual, mas seguro.

\section{A MIRAGEM DO OUTSIDER REDENTOR}

Não é, decerto, uma característica exclusiva da tradição política latino-americana acreditar em líderes messiânicos que, colocando-se na posição de outsiders, prometem instituir uma nova ordem em substituição à desacreditada - e, não raro, corrompida - ordem vigente. A própria Europa Ocidental produziu, na primeira metade do século 20, os regimes totalitários em cujos topos estavam líderes salvacionistas. Mesmo hoje discute-se a emergência de regimes híbridos no interior da Comunidade Econômica Europeia. A Hungria de Viktor Orbán se constitui em um dos casos mais emblemáticos - András Bozóki e Dániel Hegedus (2017) classificam, por exemplo, o país como "regime híbrido com limitações externas". 
Curiosamente, a situação húngara soa paradoxal porque Orbán foi um jovem líder que ajudou a derrubar o regime comunista de feição mais dura instalado no país após a invasão das tropas soviéticas em 1956. Não obstante isso, não pode haver dúvida de que a forte tradição iliberal latino-americana concorre para a ressurgência de líderes outsiders no continente que contestam a própria legitimidade das instituições da democracia representativa do tipo liberal. Trata-se já de uma vetusta tradição caudilhista que não hesita em colocar o homem providencial acima das instituições para, conectando-o diretamente com o povo, conduzir o país à sua redenção política e econômica. A lista das lideranças que interromperam o ciclo de competição eleitoral é longa: Juan Domingo Perón (e sua contraparte, Evita Perón, cujos carisma político e apelo popular superavam os do companheiro), Getúlio Vargas (no período alusivo ao Estado Novo), Fidel Castro, etc. Evita exaltou, por exemplo, a genialidade política e a absoluta excepcionalidade de Juan Perón como caudilho insubstituível:

Perón es un genio, es un conductor, es un líder y ellos piensan que, como ha pasado con otros caudillos, Perón puede ser reemplazado por otro hombre Claro que un caudillo puede ser reemplazado, pero un genio y un conductor, jamás! Con él muere el movimiento (PERÓN, 1995, p. 68).

Embora não tenha suspendido em nenhum momento o calendário (ou agenda) eleitoral, Hugo Chávez pode ser reputado, sem dúvida, como um homem providencial, um outsider, de origem militar e nacionalista, cuja ascensão resultou na derrogação do Pacto de Punto Fijo que vigorou na Venezuela durante 40 anos (1958-1998). Como sucedeu em outras experiências no continente latino-americano, a miragem do outsider redentor pode ser apontada como uma das causas relevantes para a brutal degradação do ambiente político e econômico venezuelano.

O Pacto de Punto Fijo, que surgiu após a derrubada da ditadura de Marcos Jimenez, permitiu ao sistema político venezuelano beneficiar-se de estabilidade durante quatro décadas. Copei e Ação Democrática (AD) alternaram-se no poder nesse período, mas a corrupção robusta e sistêmica, as sucessivas crises econômicas e a natureza claramente rentista e dependente do petróleo exacerbaram a percepção pública de que as elites políticas conduziam a economia de modo extrativista, apropriando-se da riqueza nacional em desfavor da população. O apoio popular dado a Chávez decorreu, portanto, do ressentimento, indignação e frustração acumulados durante 40 anos contra o corrompido sistema político forjado pelo Pacto de Punto Fijo (PANIZZA, 2000, p. 147).

Chávez intentou inicialmente chegar ao poder por meio do fracassado golpe militar de 4 de fevereiro de 1992 - o chamado 4F, comemorado pelos chavistas como data nacional, à semelhança do 26 de julho celebrado pelos castristas em Cuba. Ao sair da prisão, Chávez fundou o próprio partido e venceu a eleição presidencial de 1998, pondo fim ao desacreditado, embora longevo, sistema político criado pelo Pacto de Punto Fijo. Soara a hora do homem providencial fundar uma nova ordem social, permitindo, enfim, ao povo venezuelano usufruir dos ganhos decorrentes da atividade petroleira, algo que teria sido negado secularmente pelas elites políticas extrativistas do país. No imaginário do movimento bolivariano, Chávez encarnou a chegada do povo ao poder (BREUER, 2015, p. 18). O papel assumido de um outsider que se opõe ao sistema político corrupto e, portanto, explorador do povo favoreceu assim a ascensão de Chávez: 
Na Venezuela, por exemplo, Hugo Chávez era um outsider político que atacava o que ele caracterizava como uma elite governante corrupta, prometendo construir uma democracia mais "autêntica", que usasse a imensa riqueza do petróleo do país para melhorar a vida dos pobres. Com habilidade, e tirando proveito da ira dos venezuelanos comuns, muitos dos quais se sentiam ignorados ou maltratados pelos partidos políticos estabelecidos, Chávez foi eleito em 1998 (LEVITSKY; ZIBLATT, 2018, p. 15).

No início da trajetória política, Chávez foi influenciado pelo sociólogo argentino Norberto Ceresole, que o convenceu de que o caudilho deveria conectar-se diretamente com o povo com o apoio das Forças Armadas e, ao mesmo tempo, em que dispensava a intermediação de partidos políticos e instituições que exercem o controle horizontal. Esse pacto entre caudilho, exército e massas permitiria a realização das mudanças radicais pretendidas por Chávez e seu então mentor intelectual:

This situation underline the central thesis of Norberto Ceresole's Caudilo, Ejército, Pueblo (1999). Ceresole argues that the direct, personal, physical relation of masses with the leader is critical to the kind post-democratic legitimacy being constructed in Venezuela. In this new order of things, 'Power most remain concentrated, unified, and centralized. The people elected a person who is automatically projected into the meta-political plane, not an idea or a constitution. This is not an anti-democratic but rather a post-democratic model' (LEVINE, 2002, p. 261).

De fato, quando se aventurou no campo da teorização política, Chávez deixou claro que a democracia representativa não passava de uma "farsa" que deveria ser superada:

Desde esta perspectiva, la llamada "democracia representativa" no ha sido más que un artificio a través del cual se ha dominado a nuestros pueblos. Ya lo señalaba el Libertador: "Por el engaño se nos ha dominado más que por la fuerza". El Proyecto Nacional Simón Bolívar debe romper los límites de la farsa representativa, para avanzar hacia la conquista de nuevos espacios participativos en una primera fase de su desarrollo (CHÁVEZ, 2020, p. 8).

Obviamente, essa configuração institucional - a tríade essencial - colocava o dirigente acima das instituições típicas da democracia representativa do tipo liberal, inclusive as que fazem o controle horizontal, porquanto Ihe caberia o papel de guia iluminado do povo venezuelano e, no caso de Chávez, dos povos do continente latino-americano. Esse projeto hiperbólico voltado ao exercício de uma influência continental conferiu ao chavismo um componente distintivo diante dos movimentos políticos do passado, como o justicialismo e o getulismo que circunscreviam seus planos ao domínio nacional. Há, no entanto, uma nítida convergência neste aspecto relevante entre o chavismo e o castrismo, movimentos envolvidos em declarados projetos revolucionários de oposição à influência norte-americana, bem como a qualquer tipo de adesão a programas de conteúdo liberal. Aqui, subjaz a ideia de que a originalidade hispânica ou autóctone deve ser contraposta à tradição impessoal e individualista do liberalismo na construção das instituições do novo modelo de democracia participativa (CHÁVEZ, 2020, p. 5).

Sintomaticamente, Chávez criou os chamados Coletivos, organizações paramilitares formadas por simpatizantes do movimento bolivariano, que atuam com autorização implícita do regime, inclusive das forças armadas e forças policiais. Os Coletivos guardam similaridade 
com a configuração dos Comitês de Defesa da Revolução (CDRs) criados pelo regime cubano para fazer frente a uma eventual invasão armada norte-americana, bem como combater os "inimigos" internos da Revolução.

Percorrendo o itinerário característico dos regimes híbridos, a chamada Revolução Bolivariana começou gradualmente o processo de erosão das instituições representativas liberais em várias frentes. O Judiciário, como ramo de poder, passou, por exemplo, por seguidas alterações em sua composição, sendo afastados os magistrados que demonstravam algum tipo de independência em decisões que contrariavam os interesses políticos do regime chavista (URRIBARRÍ, 2011; TAYLOR, 2014). Do mesmo modo, outras instituições que faziam o controle horizontal foram gradualmente perdendo sua autonomia até atingirem um status de total subordinação ao Executivo agigantado como ramo de poder. O Conselho Nacional Eleitoral (CNE) é outra instituição cuja autonomia foi totalmente sacrificada aos interesses do regime bolivariano. Presidido há muitos anos pela chavista Tibisay Lucena, o CNE perdeu igualmente sua legitimidade como instituição capaz de conduzir processos eleitorais com tratamento igualitário entre incumbentes e desafiantes do regime. Como costuma ocorrer com a maior parte dos regimes híbridos, as regras eleitorais na Venezuela bolivariana são modificadas a qualquer tempo, de modo a criar evidentes constrangimentos à atuação da oposição. Assim como sucedeu com a responsabilização horizontal, a responsabilização eleitoral foi igualmente corroída por Chávez:

Apesar de limitadas, as eleições na Venezuela em 2006 ainda eram consideradas livres e justas. Em 2009, já não erao caso. Com total controle sobre o Parlamento, Tribunais e órgãos de fiscalização, o governo foi capaz de perseguir membros da oposição e distorcer severamente o seu acesso aos meios de comunicação e outros recursos, tornando quase impossível derrotar o chavismo nas urnas (GAMBOA, 2016, p. 57).

A contínua, mas segura, erosão das instituições da democracia liberal resultaram, por óbvio, no incremento robusto da corrupção governamental na Venezuela. Segundo o relatório intitulado Índice de Percepção da Corrupção 2020 da organização Transparência Internacional, a Venezuela bolivariana ocupa a 176a posição entre 180 países pesquisados. No continente americano encontra-se na última colocação entre 43 países, atrás até mesmo do miserável Haiti (170o no ranking geral da Transparência Internacional).

Nesse contexto, os poderes hiperbólicos conferidos ao Executivo resultaram no completo desmantelamento das instituições que fazem o controle horizontal, sobretudo do poder Judiciário, pondo fim ao equilíbrio decorrente do sistema de freios e contrapesos (checks and balances), pedra de toque da concepção minimalista da democracia liberal. Levitsky e Ziblatt (2018, p. 80) sustentam, por exemplo, que outsiders com inclinações demagógicas veem o sistema de freios e contrapesos "como uma camisa de força". Assim sendo, para além da miragem do outsider redentor que paira acima das instituições, outro componente constitutivo do regime híbrido conduziu a Venezuela à situação atual de degradação do seu ambiente político-institucional e econômico. Trata-se da falácia do cálculo mágico de custo zero.

\section{A FALÁCIA DO CÁLCULO MÁGICO DE CUSTO ZERO}

A Venezuela é um dos maiores produtores de petróleo do planeta, integrante da Organização dos Países Produtores de Petróleo (Opep). As elites políticas nunca tentaram verda- 
deiramente diversificar a economia do país, de modo que o desenvolvimento restou atrelado à variação de preços da commodity no mercado internacional. A abundância desse valioso recurso natural reforçou a percepção pública interna de que o país não crescia e tampouco distribuía renda por que as elites políticas se apropriavam dos ganhos da atividade petrolífera, excluindo dela o conjunto da população, caracterizando, assim, uma economia de natureza extrativista e, portanto, não inclusiva no sentido descrito por Acemoglu e Robinson (2012).

Não se tratou de uma percepção pública equivocada, uma vez que a corrupção do sistema político concebido pelo Pacto de Punto Fijo foi, sem dúvida, muito elevada, o que acabou por favorecer a ascensão do coronel Hugo Chávez, cuja proposta consistia em fazer a população venezuelana participar dos ganhos decorrentes da atividade petrolífera. A promessa de criar, no entanto, uma economia inclusiva fracassou. Chávez não só não diversificou a economia venezuelana como realizou intervenções desastradas na Petróleos de Venezuela Sociedade Anônima (PDVSA), cujo resultado foi a queda acentuada de sua produção. As pesadas transferências de recursos da PDVSA para o governo, corrupção e a expropriação de empresas de serviços limitaram exponencialmente a capacidade de investimento da empresa (PÁRRAGAS, 2020, p. 3; BUXTON, 2018, p. 412). Embora detenha as maiores reservas de petróleo bruto do planeta, a Venezuela sob o chavismo viu-se na incômoda condição de importar petróleo refinado:

La producción de crudos extra pesados en Venezuela, provenientes de La Faja del Orinoco, se ha venido incrementando en las últimas décadas, mientras que la extracción de crudos ligeros y medianos de las llamadas "áreas tradicionales" (el Lago de Maracaibo y el norte de Monagas, principalmente) ha mostrado una acelerada declinación en el último lustro, debido a la sobrexplotacion de algunos yacimientos, la falta de inversión en otros y como consecuencia de la expropiación de firmas de servicio petrolero. Esto ha hecho que PDVSA tenga serias dificultades para conseguir "diluyentes" (PÁRRAGAS, 2020, p. 1).

Em sentido amplo, as estatizações e intervenções robustas do regime bolivariano nos preços provocaram a completa desarticulação dos setores produtivos venezuelanos, fuga de capitais, hiperinflação e o êxodo de milhões de pessoas. Chávez usou a PDVSA para cooptar aliados no continente latino-americano e Caribe para o seu ambicioso projeto de internacionalizar os ideais da Revolução Bolivariana. Esse manejo político da PDVSA, colocando-a a serviço da Revolução Bolivariana em detrimento da busca da eficiência, resultou na produção decrescente de petróleo pela estatal (BUXTON, 2018, p. 412). Chávez criou então o Programa Petrocaribe, com o qual financiou 17 pequenos países do Caribe e da América Central com petróleo subsidiado pelo governo venezuelano em condições favoráveis aos importadores (CORRALES, 2015, p. 46). Em 2013 a Petrocaribe era responsável por nada menos do que 59\% do consumo total de petróleo de Cuba, 93\% do Haiti, 70\% da Nicarágua e 13\% de El Salvador, tendo celebrado ainda acordos semelhantes de petróleo subsidiado com a Argentina (CORRALES, 2015, p. 46).

Esse petróleo subsidiado impulsionou o projeto global anticapitalista e antiliberal de Chávez. Assim, o crescimento da influência venezuelana no plano subcontinental permitiu a Chávez criar a Aliança Bolivariana para os Povos de Nossa América (Alba), organização multilateral com a qual pretendeu contrapor-se à hegemonia norte-americana. O agravamento da crise econômica, contudo - resultado da intervenção estatal robusta nas atividades do livre mercado, inclusive sobre a condução do PDVSA - retirou do regime o protagonismo interna- 
cional experimentado por Chávez. A acentuada degradação do ambiente político-institucional e econômico levou o regime - agora conduzido por Nicolás Maduro, sucessor apontado por Chávez - a mudar de estratégia, preferindo acenar para os seus parceiros globais, sobretudo China e Rússia, que seus interesses somente serão mantidos ou preservados se o chavismo (agora sem Chávez) permanecer no poder (CORRALES, 2015, p. 49).

Tendo uma economia atrelada fundamentalmente à exportação do petróleo cru (e recusando-se deliberadamente a diversificá-la), a Venezuela sofreu forte impacto com a queda nos preços dessa commodity no mercado internacional. Assim, o preço do barril de petróleo vendido pela PDVSA passou de 95 US\$ no início de 2014 para 54 US\$ ao final do mesmo ano, tendo regredido a 36,6 US\$ em novembro de 2015 (CORRALES, 2015, p. 367). Embora o preço do barril tenha-se elevado - em 1엉 de outubro de 2018 o barril estava cotado em 83 US\$ ainda assim uma série de fatores impede que a economia venezuelana se recupere, tais como a robusta intervenção estatal traduzida no tabelamento oficial de preços praticados no livre mercado, expropriações e/ou nacionalizações de empresas privadas, hiperinflação, a corrupção e a utilização política da PDVSA, etc., de modo a provocar a retração econômica em razão da retirada dos incentivos à produção.

A intervenção estatal promovida pelo regime bolivariano tem sido tão robusta no campo econômico que, segundo o Índice de Liberdade Econômica da organização Heritage Foundation de 2020, a Venezuela ocupa a 179a posição. Trata-se da penúltima colocação do ranking, só superando a totalitária Coreia do Norte, uma proximidade nada honrosa que atesta a brutal degradação do ambiente econômico e político-institucional do país.

O paradoxo venezuelano é que o regime, ao propagar "o socialismo do século 20" como modelo alternativo antiliberal, parece ter servido, ao reverso, para convalidar princípios caros sustentados pela tradição liberal, especialmente pela Escola Austríaca de Economia. Assim, o robusto controle governamental de preços exercido pelo regime chavista remete à conhecida crítica sobre a incapacidade de qualquer governo calcular os custos das transações econômicas, daí resultando no fracasso dos experimentos de tabelamento ou congelamento oficial de preços. Para Mises (2010, p. 35), "onde não há um livre mercado, não há mecanismos de preços; e sem um mecanismo de preços, é impossível haver cálculo econômico". Acemoglu e Robinson (2012, p. 101-102) ressaltam, por exemplo, que os planos elaborados pelo Gosplan - o órgão responsável por todo o planejamento centralizado da antiga União Soviética - raramente passavam da forma de esboços, uma vez que, na época de Stalin, uma decisão equivocada dos planejadores poderia resultar no exílio siberiano ou, na perspectiva mais sombria, simplesmente em morte por fuzilamento.

De outro lado, a concentração hiperbólica dos meios de produção econômica nas mãos de uma única elite dirigente resultaria na perda da liberdade política, porquanto, na clássica lição de Hayek (1994, p. 101), "quem controla toda a atividade econômica também controla os meios que deverão servir a todos os fins; decide, assim, quais deles serão satisfeitos e quais não o serão".

Breuer (2015, p. 19) recorda que Chávez se recusou a diversificar a economia, preferindo optar pelo que classificava como "socialismo petrolero". Tomando uma trajetória completamente distinta da escolhida pela Venezuela bolivariana, os Emirados Árabes Unidos, que também exportavam petróleo, optaram por diversificar sua economia, convertendo a capital, 
Dubai, em um atraente hub do comércio global, alta tecnologia e turismo, enquanto Caracas encontra-se hoje no epicentro de uma crise econômica, política e até humanitária sem precedentes na história recente do continente sul-americano. Também não sem motivo, os Emirados Árabes Unidos ocupavam em 2020 o 18ㅇ lugar no ranking da Heritage Fundation.

Instituições determinam as regras do jogo que, por sua vez, moldam as interações humanas também no campo econômico, impactando no desenvolvimento de cada país (NORTH, 2018). No caso venezuelano, as regras fixadas pela Revolução Bolivariana não engendraram certeza e estabilidade para os jogadores (players), sejam pessoas, sejam organizações, como reclamam as teorias institucionalistas. Criaram, ao contrário, incentivos perversos ao desestimular completamente a busca por inovação e aumento da produtividade econômica.

Assim como a Cuba castrista que Ihe serviu de modelo, o regime híbrido venezuelano parece acreditar na falácia do cálculo mágico de custo zero, isto é, crê que é possível expandir indefinidamente os gastos governamentais como se os recursos do rentismo petroleiro fossem inesgotáveis. Essa crença apoia-se numa miríade de tradições arraigadas na cultura política latino-americana, entre a quais está a miragem do outsider redentor, o único que pode restituir ao povo o que Ihe foi tomado pelas elites predatórias. Acemoglu e Robinson (2012, p. 355) ponderam que a corrupção política sistêmica tornou os eleitores "dispostos a apoiar até mesmo déspotas em potencial como Hugo Chávez, muito provavelmente por acreditarem que somente ele seria capaz de erguer-se contra as elites políticas estabelecidas na Venezuela".

Ironicamente, as instituições criadas pela Revolução Bolivariana não conseguiram estabelecer as bases de uma economia inclusiva, tal como fora prometida por Chávez ao povo venezuelano ainda no final do século 20. Pelo contrário, as instituições forjadas e/ou reformadas pelo chavismo possuem uma nítida natureza extrativista e, ao contrário da prometida distribuição equitativa dos ganhos da renda petroleira entre a população, o que se observou foi uma concentração hiperbólica e, portanto, abusiva de poderes políticos e econômicos no agigantado Executivo.

É bem verdade que a memória coletiva da competição oligárquica decorrente do período do Pacto de Punto Fijo segue viva, constituindo-se em uma das prováveis causas para a forte, embora até aqui vencida, resistência civil nas ruas de Caracas e de outras cidades venezuelanas. A despeito disso, porém, cumpre reconhecer que essa mesma memória coletiva deve ser igualmente apontada como causa para o êxodo de venezuelanos que vão em busca de prosperidade econômica e, ainda, reconexão com as instituições que resguardam a democracia liberal.

Nesse contexto, a repressão exercida pelo regime híbrido venezuelano ao exercício da liberdade econômica afeta um dos pilares da concepção minimalista de democracia e reforça exponencialmente o entendimento de que as características autoritárias estão a prevalecer sobre os traços democráticos. Ao menos nesse campo, como vimos, a Venezuela chavista aproximou-se perigosamente dos regimes totalitários de Cuba e Coreia do Norte, situação fática que deve ser levada em conta pelos estudiosos dos regimes híbridos. 


\section{CONCLUSÕES}

As instituições da democracia representativa do tipo liberal são suscetíveis de contínuas reformas visando ao seu aprimoramento. A despeito disso, a congruência entre as preferências dos representados e os resultados efetivamente apresentados pela democracia liberal engendram, sem dúvida, uma tensão permanente e, no limite, crises políticas e econômicas eclodem com graves consequências. Como ressalta Borges (2011, p. 41), todas as democracias contemporâneas têm em comum instituições representativas, partidos, eleições, parlamentos e governos. Trata-se da constituição de um arcabouço institucional mínimo que induz à resolução de conflitos, à responsabilização dos dirigentes e à alternância dos grupos ou partidos no poder sem derramamento de sangue, como pretendeu Popper. O desiderato de muitos regimes híbridos de superar tais instituições típicas da democracia liberal não tem chegado, no entanto, a bons resultados. O caso do regime bolivariano apresenta-se como emblemático porque substituiu o sistema do Pacto de Punto Fijo cuja competição oligárquica durou 40 anos até ser pulverizado, como um castelo de cartas, pela ascensão do coronel Hugo Chávez, o homem providencial, o outsider redentor que viria inaugurar uma nova ordem social emancipadora.

Depois de 20 anos de Revolução Bolivariana, com e sem Chávez, é possível afirmar que, sem garantir o funcionamento adequado de algumas instituições - como eleições livres e justas - típicas da concepção minimalista, a democracia não pode subsistir como espaço institucional de resolução de conflitos e alternância pacífica de grupos políticos no poder. Os constrangimentos institucionais formais e informais gradualmente impostos à oposição e aos movimentos civis pelo regime chavista resultaram, assim, "em um espaço político desigual", de modo a colocar a Venezuela como uma das democracias "de menor qualidade da América Latina" (ANDRADE; REMíGIO, 2016, p. 174). Sem embargo, o catálogo de ataques praticados às instituições de controle horizontal e eleitoral (vertical) é hoje robusto, afastando qualquer dúvida quanto à erosão da democracia liberal no país, mesmo em seus arranjos mínimos. Se o regime bolivariano mantém o simulacro ou verniz democrático de algumas instituições - como procedimentos eleitorais cujas regras, no entanto, modifica a qualquer tempo para favorecer os incumbentes - o objetivo não parece ser outro que não escapar às sanções econômicas internacionais que podem agravar ainda mais o já degradado ambiente político e econômico.

Tentando compreender como as instituições democráticas representativas podem ser demolidas por dentro (e não mais por golpes conduzidos por militares exaltados), Levitsky e Ziblatt (2018, p. 81) apontaram, a partir da analogia com uma imaginária partida de futebol, três estratégias por meio das quais os autoritários eleitos buscam consolidar seu poder: capturar os árbitros, tirar da partida importantes jogadores do time adversário e reescrever as regras para inverter a situação do jogo contra oponentes. Sobre o caso específico de Hugo Chávez, não hesitaram em enquadrar o líder venezuelano como "autoritário" por ter utilizado as três estratégias no manejo da chamada Revolução Bolivariana (LEVITSKY; ZIBLATT, 2018, p. 180).

O foco principal do estudo de Levitsky e Ziblatt consistiu em escrutinar a possibilidade de o governo Donald Trump converter a democracia consolidada norte-americana em uma autocracia. Escapou-lhes, provavelmente por isso que, no caso venezuelano (assim como na 
maioria dos casos latino-americanos), a forte tradição iliberal do continente ao sul dos Estados Unidos fornece ampla justificação para o estabelecimento de regimes híbridos. A vertiginosa degradação do ambiente político-institucional e econômico na Venezuela bolivariana teve, assim, como causas, entre outras, a miragem do outsider redentor e a falácia do cálculo mágico de custo zero. Tais causas manifestaram-se com bastante intensidade na trajetória política de Hugo Chávez, bem como no curso da denominada Revolução Bolivariana, mesmo após o desaparecimento de seu grande líder. O caso venezuelano não é, decerto, único, mas segue um padrão que se verifica em outros países da América Latina. Trump pode ter representado um ponto de inflexão autoritário na história política norte-americana; na América Latina, porém, a ascensão de outsiders políticos com discursos messiânicos é mais comum do que seria desejável para democracias que buscam consolidação.

Curiosamente, o contraste acentuado entre os Estados Unidos ricos e democráticos e a América Latina política e economicamente instável não tem servido como motivo reflexivo para que se tente modificar a trajetória dependente da robusta tradição iliberal, mas é utilizado frequentemente como argumento para justificar a erosão gradual, mas segura, das instituições da democracia liberal. Supostamente capturada por elites políticas predatórias (ou extrativistas, segundo o jargão de Acemoglu e Robinson), a democracia liberal seria a causa principal do atraso político-institucional e econômico latino-americano. Para Chávez, como vimos, "a farsa representativa" precisava ser rompida e superada por "novos espaços participativos". Ocorre que, ao rechaçar as instituições que estruturam a concepção mínima de democracia, a Revolução Bolivariana não produziu mais participação política e tampouco criou uma economia inclusiva que rompesse com o histórico rentismo petroleiro. O iminente colapso venezuelano sugere, portanto, que regimes híbridos necessitam, se desejarem sobreviver, preservar as instituições que estruturam a concepção minimalista de democracia.

\section{REFERÊNCIAS}

ACEMOGLU, D.; ROBINSON, J. Por que as nações fracassam - as origens do poder, da prosperidade e da pobreza. São Paulo: Elsevier, 2012.

ANDRADE, M.; REMÍGIO, R. O hibridismo da democracia e a solidez das instituições: uma análise teórica sobre as dimensões de uma democracia em desenvolvimento. Revista de Estudos Internacionais (REI). João Pessoa, v. 7, p. 167-186, 2016.

BORGES, R. Minimalismo schumpeteriano, teoria econômica da democracia e escolha racional. Revista de Sociologia Política, Curitiba, v. 19, n. 38, p. 27-42, fev. 2011.

BOZÓKI, A.; HEGEDUS, D. Um regime híbrido com limitações externas - a Hungria na União Europeia. Relações Internacionais, Lisboa, n. 55, set. 2017, p. 99-114.

BREUER, H. Éramos felices sin saberlo? Viejas y nuevas fracturas en la sociedad venezolana. Nueva Sociedad, $\mathrm{n}$. 257, p. 15-26, mayo/jun. 2015.

BUXTON, J. Venezuela: Deeper into the Abyss. Revista de Ciência Política, v. 38, n. 2, p. 409-428, 2018.

CHÁVEZ, H. El Libro Azul. Disponível no sitio: www.sudeban.gob.ve. Acesso em: 20 set. 2020.

CORRALES, J. Autocratic Legalism in Venezuela. Journal of Democracy, v. 26, n. 2, p. 37-51, abr. 2015.

DAHL, R. A poliarquia. São Paulo: Edusp, 2005.

DIAMOND, L. Thinking about Hybrid Regimes. Journal of Democracy, v. 13, n. 2, p. 21-35, abr. 2002.

GAMBOA, L. Venezuela - aprofundamento do autoritarismo ou transição para a democracia? Relações Internacionais, p. 55-66, dez. 2016.

HAYEK, F. O caminho da servidão. Rio de Janeiro: Biblioteca do Exército e Instituto Liberal, 1994.

HERITAGE FOUNDATION. 2020 Index of Economic Freedom. 2020. Disponível em: www.heritage.org. p. 1-524. Acesso em: 10 fev. 2021. 
KORNBLITH, M. Chavismo after Chávez? Journal of Democracy, v. 24, n. 3, p. 47-61, jul. 2013.

LEVINE, D.; MOLINA, J. E. Calidad de la Democracia en Venezuela. America Latina Hoy, 62, p. 157-175, 2012.

LEVINE, D. The Decline and Fall of Democracy in Venezuela: Ten Theses. Bulletin of Latin American Research, The University of Michigan, v. 21, n. 2, p. 248-269, 2002.

LEVITSKY, S.; MURILLO, M. V. Building Institutions on Weak Foundations. Journal of Democracy, v. 24, n. 2, p. 93107, abr. 2013.

LEVITSKY, S.; ZIBLATT, D. Como as democracias morrem. São Paulo: Zahar, 2018.

MISES, L. A ação humana - um tratado de economia. São Paulo: Instituto Ludwig von Mises Brasil, 2010.

NORTH, D. Instituições, mudança institucional e desempenho econômico. São Paulo: Três Estrelas, 2018.

PANIZZA, F. New wine in old bottles? Old and New Populism in Latin America. Editorial/Bulletin of Latin American Research, 19, p. 145-147, 2000.

PÁRRAGAS, M. Venezuela importando petróleo? Porquê? p. 1-4. Disponível em: www.prodavinci.com. Acesso em: 17 out. 2020.

PERÓN, E. Historia del Peronismo. Buenos Aires: CS Ediciones, 1995.

POPPER, K. A sociedade aberta e seus inimigos. Belo Horizonte: Editora Itatiaia, 1998.

SCHUMPETER, J. Capitalismo, socialismo e democracia. Disponível em: www.ordemlivre.org. Acesso em: 11 dez. 2013

TAYLOR, M. The Limits of Judicial Independence: A Model with Illustration from Venezuela under Chávez. Journal of Latin American Studies, Cambridge Journals, v. 46, Issue 2, p. 229-259, May. 2014. Disponível em: www.cambridge.org.core. Acesso em: 15 jan. 2021.

TRANSPARÊNCIA INTERNACIONAL. Índice de percepção da corrupção 2020. p. 1-61. Disponível em: www.transparency.org. Acesso em: 15 jan. 2021.

URRIBARRÍ, R. Courts between Democracy and Hybrid Authoritarianism: Evidence from the Venezuelan Supreme Court. Law \& Social Inquiry, v. 36, Issue 4, p. 854-884, 2011.

URRIBARRÍ, R. Venezuela (2015): Un Régime Híbrido en Crisis. Revista de Ciência Política, v. 36, n. 1, p. 365-381, 2016. 